\title{
Research on the Contemporary Value of Yanan Sports practice Spirit
}

\author{
Xiangle Meng ${ }^{1, a^{*}}$, Jin lun Jia ${ }^{1, b}$, Qing fang $\mathrm{Su}^{1, \mathrm{c}}$ \\ ${ }^{1} 580$ ShengDi Road Yanan Shaanxi Province China \\ amz7006@126.com, bjiajinlun@126.com, jiajinlun@126.com
}

Keywords: Yanan Sports Practice spirit; Connotation; Denotation; Contemporary value; Harmonious society

\begin{abstract}
Sports practice spirit in Yanan period is an important part of Yanan spirit, it is very meaningful for us to develop sports and build harmonious society by inheriting and carrying forward the spirits in new period. First of all, the paper explained the connotation and denotation of Yanan sports practice spirit. The connotation was the experience and knowledge that the CPC concluded in developing sports industry in Yanan period, and the denotation was the outward manifestation of the connotation, which included a method to pursuit ideal, serving the people heart and soul, relying on one's own efforts, working hard and perseveringly, seeking truth from facts, and collectivism and so on. Based on understanding deeply its connotation and denotation, and combined with the reality situations of China, the research analyzed seriously its contemporary values. The conclusions show that the contemporary value is reflected in three aspects. Firstly, it can provide experiences for making sports policies in new era. Secondly, it can help to promote Chinese sports spirit in contemporary society, and finally it can provide demonstration for carrying out the national fitness in harmonious society.
\end{abstract}

\section{Introduction}

Yanan period is from October 19, 1935 to March 23, 1948. after the Long March, Mao Zedong led the workers' and peasants' red army arrived at Wu Qi town (now in Wu Qi County) of Northern Shaanxi China, later, to command the war of liberation better, Mao Zedong left Wu Qi to North China area, a total of thirteen years.

In the period, the sports industry in Yanan revolution border had developed rapidly, and gave birth to the "Yanan sports practice spirit", which was also known as "Yanan sports spirit"(the below is same). Yanan sports spirit refers to the sum of all the positive theory and practice experiences formed by the Communist Party of China (CPC) in developing sports industry in Yanan period.

During the years, sports had developed from less to more, from monotonous to rich, from the physical exercise to the sports theory research. Finally, a series of knowledge and experiences were formed the connotation of Yanan sports spirit. E.g., why should we carry out sports? Who is going to take part in sports? How to carry out the movement as well as how to carry out better? The denotation is a manifestation of the nature of things. The conclusions of the studies in the denotation of Yanan sports spirit are consistent. Its denotation is that Sport is considered to be a method to pursuit ideal, to serve the people heart and soul, to rely on one's own efforts, to work hard and perseveringly, to seek truth from facts, and to be collectivism [1].

"Take history as a mirror, know how the things rise and fall". Today, a deep understanding of the 
connotation and denotation of Yanan sports spirit is conducive to understand its contemporary value profoundly, to inherit and carry forward Yanan sports spirit better under a new situation.

\section{Yanan Sports Spirit's Contemporary Values}

Yanan period has been away from us, but the Yanan sports spirit should be like "Yanan spirit" shinning forever. The contemporary values of Yanan sports spirit are reflected in the following three aspects.

Provide Experiences for formulating Sports Policy. In the 30's of last century, natural environment was harsh, economy and culture were backward, social development was extremely slow. In such context, develop sports industry was extremely difficult. However, just a few years after the CPC arrived, sports in Northern Shaanxi area had had great changes not only in school sports, mass sports, various competitions sports, but also in sports equipment production, sports organizations and sports system, sports awareness etc. Why have it had these great changes? What' more, at the same time, the Yanan border had to face a severe military situation that resisted the Japanese and Kuomintang attack. In my opinion, the key is that develop several reasonable policies based on the background of the times.

At that time, the background of the times was "Anti-Japan and survival, all should serve for the overall situation". Therefore, improve the quality of the body through physical exercise had become a way of the Anti-Japanese national salvation. In order to carry out sports better, many association of sports organizations were established, sports systems were developed to ensure the goal and direction of sports. Meanwhile, Heads of revolution government always stressed in different occasions that sports should meet the era background and the current demands. Such as Mao Zedong put forward "do exercises more, fight against Japan well" at the opening ceremony of the eight one sports games, He Long pointed out that sports should be militarization and normalization in "nine one expand Games". So it was obvious that sports in Yanan were highly targeted, and the sports system effectively guaranteed to carry out the movement. Therefore, the sports at that time regardless of the content or form were in line with the social environment, and received good results. On one hand, sports activities enriched amateur life, enhanced the quality and combat effectiveness of people and soldiers, on the other hand, it improved the awareness level of sports value. So the experiences tell us that formulate and implement policies should give full consideration to the basic condition and demands of society, improve the Pertinence, forward-looking and feasibility of sports policy. These are the most valuable experiences and inspiration.

Nowadays, relationship among sports, politics, economy etc is getting more closed, formulate policies should be better in line with national conditions, should considerate them coordinately. After review the sports policy since China's reform and opening up policy, we can find that there are many obvious deficiencies. Sports especially competitive sports have been given a strong political overtone, which have regarded as "a tool of showing national image and power". There is no denying that it indeed plays a very important role in the past thirty years, but the situation is not the situation in the past, so sports policy today no longer pay too much attention to its political function, it should take into account people' demands for health, and its goals should be transferred to solve the contradiction between the people's growing demands for sports culture with poor sports functions. Meanwhile, sports policy should excavate economic and cultural value of sports, be beneficial for the comprehensive development of economy, culture and sports. Zhang Xuefei stressed in his research on sport strategic value, China's sports should highlight the strategic value of adolescent health, 
economic and cultural value, should coordinate the value orientation of strategy of national sports development well, should return to the track of china's economic strength and cultural strength [2]. Fortunately, our country sports policy has experienced three major strategic adjustments since the 70's of last century. The bases of adjustment are "nation situation" and "world situation". Indeed, all the adjustments have promoted development of sports industry effectively.

Reconstruction and purify China contemporary sports spirit. Sports spirit is the highest product, soul and essence of sports. It reflects the human pursuit of value, excellent quality qualities and lofty ideal, and also is precious spiritual wealth of human society [3]. currently widely accepted sports spirit includes "peace and freedom spirit", "fair competition", "pursuit of excellence", "sportsmanship", "contract spirit" [4] and the "Olympic spirit". All these spirit play key functions that not only promote sports to standardization, fairness, high level, but also to popularization.

However, with the over-commercialization of sports, sports spirit is facing increasingly serious challenges. At present, the Chinese sports spirit is suffering erosion gradually. Firstly, unfair play problems always appear in games, sports humanistic spirit is in danger, so competitive sports has been pushed into a dilemma, and lost its charm greatly [5]. For examples, during the Twelfth National Games, Beijing team stroked in seven rugby team's final match, and Sichuan synchronized swimmers to refuse to accept the silver medal and announced their retirement immediately. What had caused these two accidents? "Unfairly referee". In fact, the final reasons are lack of sports sprit caused by the distribution of interests and rights. Secondly, school sports and mass sports are provided for enhancing the people's physique, but in relatively undeveloped areas, sports industry is poor even very poor. "Less time, lack of facilities, lack of participation motivation" is main factors [6, 7]. Of cause, the reasons mentioned above do hinder the mass from exercise, however, a famous saying in china goes that, "do it when you have the conditions, still do it by creating conditions when do not have the conditions". Obvious, it indicates that the people's initiative is more important to some extent. Compared with developed areas, people in less developed areas are lack of sports spirit and sports view. If they are able to inherit and carry forward the Yanan sports spirit, to fully understand the effect that sports influence on the ideal, can now sports development in less developed areas be improved significantly.

As for as china concerned, Yanan sports spirit should be the pillar of contemporary chinese sports spirit under the tide of market economy, be the inherent power that helps to promote the sports spirit, be the core content of Chinese-style sports spirit.

Provide paradigm for the mass fitness in china. The harmonious society is emphasized on harmonies that exist in oneself, people and people, people and nature, its core is "people-oriented" [8]. In the process of construction a harmonious society, sports undertake an important historical mission.

In 1995, our country launched the "national fitness program" and "Olympic honor program" to lighten the health level of the people, and to improve the level of competitive sports. But in the implementation process, Olympic honor program was placed in absolute dominance, and the national fitness program was almost a formality. As a result, competitive sports had received certain effects, but the national health level especially adolescent physique had declined. How much the price is high!

Today, China's comprehensive power is among the highest in the world, what's more, after the Beijing 2008 Olympic Games, something must be changed. These changes reflect in two "transits". One is that the mass transit their attention from sports' motivation and promotion national strength to 
care for their own physical and mental health. The other is that sports transit from "elite sports" to "mass sports". These changes can allow people to enjoy the national sports development, the progress of the benefits brought about by the harmonious society, to experience the happiness. However, in fact, the changes do not achieve its desired objectives effectively and exactly, because to achieve the national fitness goals can not just depend on making policies, adding fitness facilities and fitness stations as well as a large number of matches and performances in festivals, still more to cultivate sports ideal and consciousness.

Sports in Yanan period are considered as the most widely mass sports in China today. At that time, the participants included the heads of the central government, ordinary people, soldiers, intellectuals and businessmen, farmers, workers etc.; made sports facilities, formulated rules and standards by themselves; the prizes were only some daily necessities, but people were still contented and prepared carefully for another game..... [9] What's a really nice picture! Visible, the paradigm that the CPC used for carrying out the sports is very effective. Indeed, regarding sports as a link, the CPC unite all forces that can be united, publicize the spirit of patriotism, cultivate collective spirit, these measures, As a result, made the border society become more harmonious and unprecedented unity, and send a large number of effective strength for resisting Japan.

Therefore, although our sports industry has made many progresses today, the paradigm still has positive reference for the development of national fitness campaign.

\section{Conclusions}

Although Yanan sports spirit is formed in the old china which has its specific background, In the new historical period, studying Yanan sports spirit deeply is still helpful to eliminate many disharmonious factors in sports field. Especially for a long period of time in the future, with the diversification of people thought deeply and driven by economic interests increased, inherit and carry forward Yanan sports spirit has important practical significance for the sublimation of the Chinese sports spirit, the transition from the major sports country to the world sports power and the construction of harmonious society.

\section{Acknowledgements}

The research was supported by Department of Education Special Fundation of ShanXi Province. Fundation code: $14 \mathrm{JK} 1819$.

\section{References}

[1] T. Dang: Journal of Xi'an Physical Education, Vol. 27 (2010) No.5, p.562-565. (In Chinese)

[2] X.F. Zhang: Sports Science, Vol. 34 (2014) No.1, p.58-65. (In Chinese)

[3] L. Huang: Sports Science, Vol. 27 (2007) No.6, p.88-96. (In Chinese)

[4] Z.X. Wang: Journal of Physical Education, Vol. 18 (2011) No.18, p.42-45. (In Chinese)

[5] L.H. Tang, Y.H. Peng: Journal of Nanjing Sport Institute (Social Science Edition), Vol. 23 (2009) No.5, p.73-76. (In Chinese)

[6] G. Zhu, H. Ma: Journal of Chengdu Sport University, Vol. 34 (2014) No.3, p.15-18. 


\section{(In Chinese)}

[7] L.X. Le: Teaching and management, Vol. 34 (2010) No.5, p.55-56. (In Chinese)

[8] S.H. Xiao: Search, Vol. 34 (2013) No.11, p.256-258. (In Chinese)

[9] Y.Z. Cheng: Research on the CPC'S Sports Work During the Anti-Japan War (MS., Wuhan Sports Institute, China 2010), p.8-12. (In Chinese) 